AJHSE Vol: 2 (2): 45-54, 2021

DOI: $10.52417 /$ ajhse.v2i2.140

Accepted Date: August 20, 2021

(C) 2021. CC License 4.0

www.ajhse.org

\title{
PERCEPTION OF HAND HYGIENE HABIT AND HEALTH IMPLICATIONS AMONGST THE STUDENTS OF A TERTIARY INSTITUTION IN SOUTHWESTERN NIGERIA
}

\author{
${ }^{* 1}$ Adebambo, A.A.R., ${ }^{2}$ Ojo, F.T. \& ${ }^{3}$ Uthman, T.O.O. \\ ${ }^{* 1,2 \& 3}$ Department of Biological Sciences Tai Solarin University of Education, P.M.B 2118, Ijagun Ogun State, Nigeria \\ *Corresponding Author's E-mail: adebamboadesoji@yahoo.com
}

\begin{abstract}
耳 and hygiene habits and the knowledge of their health implications were investigated among students of a tertiary institution in Southwestern Nigeria. A descriptive survey guided by twenty research questions and four research hypotheses was carried out. A total of 400 undergraduates were randomly selected across the five colleges in the University. The highest respondents were of less than 20 years of age (74\%), followed by 21 25 years $(25 \%)$. Two hundred and four $(51 \%)$ of the respondents claimed that water which is vital to hand hygiene habit is scarce, 124 (31\%) wash hands before meal only, 96(24\%) wash hands after toileting, however, 368 (92\%) had knowledge that good handwashing habit prevents diseases and infestations. Massive campaigns and awareness are subjacent to improve the culture and habit of hand-washing. Hygiene education should be introduced in all academic curricula to guide in the prevention of the rapid spread of epidemics of which hand seems the first contact of disease infestation.
\end{abstract}

Keywords: Hand Hygiene, Perception, Health implications, Nigeria, Tertiary institution

LICENSE: This article by African Journal of Health, Safety and Environment (AJHSE)is licensed and published under the Creative Commons Attribution License 4.0 International License, which permits unrestricted use, distribution, and reproduction in any medium, provided this article is duly cited.

COPYRIGHT: The Author(s) completely retain the copyright of this published article.

OPEN ACCESS: The Author(s) approves that this article remains permanently online in the open access (OA) model

QA: This Article is published in line with "COPE (Committee on Publication Ethics) and PIE (Publication Integrity \& Ethics)". 


\section{INTRODUCTION}

It is a fact that washing of hands brings about hand hygiene, and this is well known as one of the most significant activities essential for the reduction of transmission of infectious diseases particularly in the hospitals, (Zapka et al., 2017). Hand hygiene generally refers to different methods of killing microorganisms which may be present on hands by either washing of hands or sanitizing it. It is essential in reducing infectious disease transmission (Otokunefor and Princewill, 2017), while the unhygienic hands may also harbor infective stages of Protozoans or worms. Hand hygiene is one of the fundamental health behaviours, most simple, effective and cheap way to prevent the spread of infectious diseases (CDCP 2013)

The hand washing habit as part of its hygiene is being supported with a day campaign and practice known as global hand washing day appointed since October 15, 2008 by United Nation General Assembly and which is celebrated annually. This day is to support a global and local culture, raising the awareness about the benefits and state of hand washing with soap in each country as a key approach to disease prevention (GHP,2017).

However, the concept of hand sanitization has been in place right from the start of hand hygiene campaign by Semmelweis, (World Health Organization 2009). Pires et al. (2017) declared that hand washing habit is a very strategic hygienic practice that is pivotal to lifestyle of which everyone should be mindful of, in order to reduce transmission and incidence of diseases as most death in developing countries is attributed to poor level of public hygiene. Also, about two billion people are involved in poor faeces disposal, experiencing unavailability of safe and drinking water (Didier et al., 2009) and inadequate knowledge of poor hand washing habit. The poor level of public hygiene in developing countries Nigeria inclusive, is as a result of poor faeces disposal, inadequate knowledge of good sanitation practice, lack of infrastructure, such as pipe borne water and electricity, making water not readily availabile. This is a fact corroborated by Curtis et al., (2003) that at the end of $20^{\text {th }}$ century, two billion people still have inadequate access to proper sanitation with one billion without enough water to drink.

Hand wash as part of hygiene is a habit that saves lives, and washing with soaps are germane in reducing pathogens (Burton et al.2011). It is also a best approach to prevent infection transmission (Pires et al, 2017). The rate of hand wash amongst health workers who should know better is poor. However, between knowledge and practice, the knowledge on various aspect of hand washing is better in doctors who had practice rate of $23 \%$ compared to nurses (28\%) Songa et al., (2015). A Percentage of 37.6 of medical students in Kenya washed their hands regularly after attending to patients with the fear that failure to wash hand can lead to infection (Songa, 2015).

Nair et al. (2014) reported a low knowledge of hand hygiene (9\%) among medical and nursing students in India, however the nurses' knowledge was significantly better than the medical students. Attention of hand hygiene habit has been mostly concentrated on infants and children whereas adolescent and adults have not been adequately informed on the need to imbibe the practice with the expectation that they should know. However, these populations may also be consequent to poor practice of the habit, in view of this, the study was undertaken to examine the perception of hand hygiene habit and health implications amongst the students of a tertiary institution in Southwestern Nigeria. The aim of the study was to examine the perception of hand hygiene habit and health implications amongst the students of a University of Education in Southwestern Nigeria. 


\section{MATERIALS AND METHOD STUDY AREA}

The study was carried out in Tai Solarin University of Education, Ijagun, in Odogbolu Local Government area of Ogun State, Southwest Nigeria. The University is located in the forest zone belt of the Country and lies between $6.82^{\circ} \mathrm{N}$ latitude and $3.92^{\circ} \mathrm{E}$ longitude (Oke, 2012). It consists of heterogeneous population of different cadre of university workers and Students. The accommodation for the students consists of the University and private hostels, the University and the town experience epileptic supply of electricity and exist with no municipal pipe borne water, possibly as a result of its hilly position, but there exist deep wells and bore holes in the hostels at various distances to be fetched for different individual purposes.

\section{RESEARCH DESIGN}

The research design used was descriptive survey. It is a descriptive survey in which no variable was manipulated since the phenomenon had occurred already.

\section{SAMPLING TECHNIQUES}

Four hundred (400) undergraduates of Tai Solarin University of Education cutting across the five colleges of the University were selected through simple random technique for the study. The study was carried out between May and September, 2019. However, the distribution of the questionnaires was done at the presentation of the students' identity card to forestall repetition, while confidentiality of respondents was taken to cognizance, the 400 respondents were males and females students covering $100-400$ level in the University.

\section{INSTRUMENT FOR DATA COLLECTION}

A self-designed questionnaire which contained both structure and unstructured items was used as research instrument of data collection. The questionnaires were administered to the respondents and retrieved on the spot. The response categories included available and non-available, Yes and No responses as well as fill in the gap.

\section{VALIDITY OF THE RESEARCH INSTRUMENT}

Draft copies of the research instrument were given to experts in the area of Health Education, Parasitology and Microbiology who examined it in terms of contents, relevance, coverage, phrasing upon which their observations, suggestions and corrections were considered in the modification of the final draft of the questionnaire.

\section{RELIABILITY OF THE RESEARCH INSTRUMENT}

Twenty copies of the questionnaire were distributed to undergraduate students outside the study area at two weeks interval upon which Cronbach-alpha was used to determine the reliability. A reliability co-efficient of 0.81 obtained was considered suitable enough for the research instrument reliability for relevant data collection. 


\section{DATA ANALYSIS}

Data generated were collated and verified to ensure completeness and accurate documentation. Data was analyzed using descriptive statistics of frequency counts, percentages, pie chart and inferential statistics of chi square as appropriate. SPSS version 18 was used for the analyses.

\section{RESULTS}

Table 1 shows the demography of the respondents Two hundred (200) (50\%) of each of males and females are in the distribution. The highest respondent of 296 (74\%) fall within the age distribution of 15 - 20 years, the least was within the age brackets of 26-30years which is $4(1 \%)$ while 100 (25\%) of the respondents fall in the age bracket of 21-25 years.

The use of deep well 204 (51\%) was the major source of water followed by borehole 172 (43\%), while the least were those that visited stream or river $4(1 \%)$ and public water $44(11 \%)$ as for those living in a nearby town with municipal water facilities presented in Figure 1. It was also revealed that 196 (49\%) of respondents have access to water while 204 (51\%) have water not readily available to them.

The respondents have different time that was prominent for hand wash, the highest 124 (31\%) were before meal; 80 (20\%) respondents reported hand washing after each day's work; 96 (24\%) washed hand after toileting, 4 (1\%) each during bath and before meal, after toilet and before meal (Table 2a). Ninety-two (92\%) of the respondence were aware that hand wash prevents disease while just eight (8\%) were not aware of those diseases are prevented through hand wash (Table $2 \mathrm{~b}$ ). Time used to wash hand is an important factor to ensuring proper hygiene, however 124 respondents (31\%) spend less than one minute while $140(35 \%)$ spend more than one minutes $132(33 \%)$ never took cognizance of the time spent on hand wash (Table $2 \mathrm{c}$ ).

In the best practice of handwash in terms of methodology; and for this investigation 116 (29\%) indicated the use of running water to wash hands while 268 (67\%) used non-running water but confined in a container (Table 3). On respondents' knowledge on prevention of diseases through hand hygiene, majority (92\%) stated that washing of hands prevents diseases. Arrays of diseases were recorded as respondents' knowledge of diseases types that can be contacted through non-washing of hand amongst are Cholera 128 (32\%) which is the most recognized disease, Ebola representing $40(10 \%)$, Typhoid 64 (16\%), food poisoning 8 (2\%) combination of Ebola, Cholera and Diarrhea 28 (7\%) while non-contagious disease like malaria and appendicitis were recorded by 36 and 4 respondents representing (4\%) and (1\%) respectively in Table 4.

This investigation shows that $304(76 \%)$ respondents have knowledge of hand sanitizers, amongst which $54(17.8 \%)$ have used a brand of hand sanitizers for hand sanitation, $68(17 \%)$ had no knowledge, while 28(7\%) gave no response, amongst the respondents (Table 5). Sixty (60\%) used water and soap than their male counterparts (55\%) who used water only to wash their hands. Respondents between 21 and 25 years (56\%) used water only while (44\%) spent more than one minute in carrying out their hand hygiene (Table 6). 
Table 1: Demography of the respondents

\begin{tabular}{llll}
\hline Distribution & Variable & NUMBER & PERCENTAGE (\%) \\
\hline Gender & Female & 200 & 50.0 \\
& Male & 200 & 50.0 \\
& & & \\
Age & Below 20 & 296 & 74.0 \\
& $21-25$ & 100 & 25.0 \\
& $26-30$ & 4 & 1.0 \\
\hline
\end{tabular}

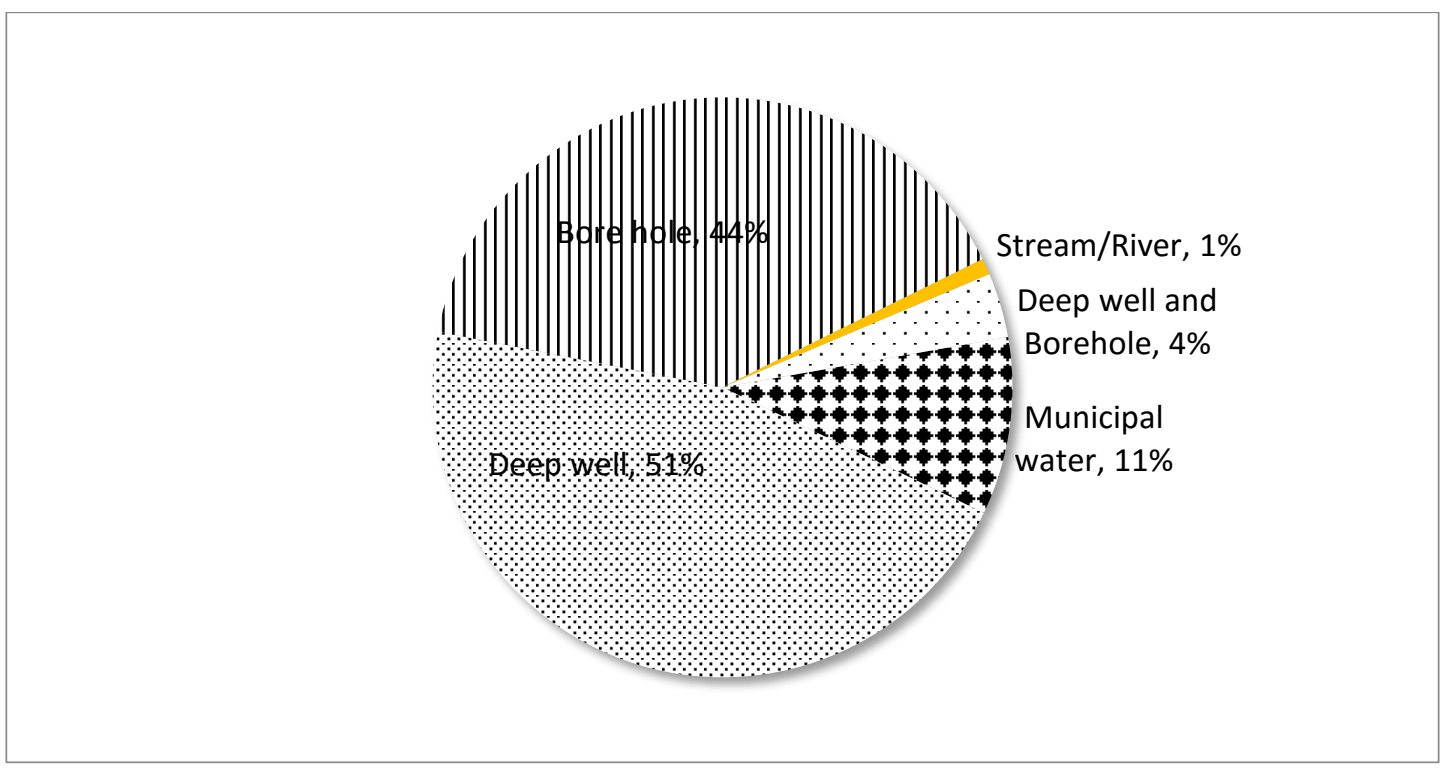

Figure 1: Sources of water used by the respondents

Table 2a: Time respondents wash hands

\begin{tabular}{llrr}
\hline S/N & \multicolumn{1}{c}{ Period of Hand Wash } & Number of Respondents & \% \\
\hline 1. & During bath & 12 & 3.0 \\
2. & After Toilet & 96 & 24.0 \\
3. & After each day's work & 80 & 20.0 \\
4. & Before meal & 124 & 31.0 \\
5. & Random wash & 76 & 19.0 \\
6. & After farm work & 4 & 1.0 \\
7. & During bath and before meal & 4 & 1.0 \\
8. & After toilet and before meal & 4 & 1.0 \\
\hline & Total & $\mathbf{4 0 0}$ & $\mathbf{1 0 0}$ \\
\hline
\end{tabular}

Table 2b: Respondents' knowledge on prevention of diseases through hand wash

\begin{tabular}{lcc}
\hline \multicolumn{1}{c}{ Status } & Number of Respondents & \% \\
\hline Hand wash prevent diseases & 368 & 92.0 \\
Hand wash do not prevent diseases & 32 & 8.0 \\
\hline Total & $\mathbf{4 0 0}$ & $\mathbf{1 0 0}$ \\
\hline
\end{tabular}


Table 2c: Duration used for washing of hand by the respondents

\begin{tabular}{llcc}
\hline S/N & \multicolumn{1}{c}{ Time Used } & Number of Respondent & \% \\
\hline 1. & Less than 1 minute & 124 & 31.0 \\
2. & More than 1 minute & 140 & 35.0 \\
3. & Don't know & 132 & 33.0 \\
4. & No response & 4 & 1.0 \\
\hline & Total & $\mathbf{4 0 0}$ & $\mathbf{1 0 0}$ \\
\hline
\end{tabular}

Table 3: Respondents attitude to water usage during hand wash

\begin{tabular}{llcr}
\hline S/N & \multicolumn{1}{c}{ Water usage } & Number of Respondent & \% \\
\hline 1. & Running water & 116 & 31.0 \\
2. & Non-running water & 268 & 67.0 \\
3. & No response & 16 & 4.0 \\
\hline & Total & $\mathbf{4 0 0}$ & $\mathbf{1 0 0}$ \\
\hline
\end{tabular}

Table 4: Diseases known by the respondents that can be contracted through non-washing of hand

\begin{tabular}{llrr}
\hline S/N & \multicolumn{1}{c}{ Diseases } & Number of Respondents & \% \\
\hline 1. & Ebola & 40 & 10.0 \\
2. & Cholera & 128 & 32.0 \\
3. & Typhoid & 64 & 16.0 \\
4. & Diarrhea & 8 & 2.0 \\
5. & Amoebasis & 8 & 2.0 \\
6. & Malaria & 36 & 4.0 \\
7. & Tuberculosis & 8 & 2.0 \\
8. & Cough & 4 & 1.0 \\
9. & Appendicitis & 4 & 1.0 \\
10. & Food poisoning & 8 & 2.0 \\
11. & Rashes "unidentified" & 4 & 1.0 \\
12. & Ringworm & 8 & 2.0 \\
13. & Malaria \& Tuberculosis & 4 & 1.0 \\
14. & Ebola \& Cholera & 8 & 2.0 \\
15. & Ebola, Cholera and Diarrhea & 28 & 7.0 \\
16. & Cholera \& diarrhea & 8 & 2.0 \\
17. & Cholera \& typhoid & 24 & 6.0 \\
18. & Unseen germs & 8 & 2.0 \\
& Total & $\mathbf{4 0 0}$ & $\mathbf{1 0 0}$ \\
\hline
\end{tabular}

Table 5: Respondents Knowledge of hand sanitizer in relation to gender

\begin{tabular}{cccccc}
\hline \multicolumn{2}{c}{ Distribution Variable } & \multicolumn{3}{c}{ Knowledge } & \multicolumn{2}{c}{ Total } \\
\cline { 3 - 5 } & & No & Yes & \\
\hline Gender & Male & 40 & & 115 & 155 \\
& Female & 28 & & 189 & 217 \\
Total & & 68 & 304 & 372 \\
\hline$X^{2}(1)=10.077, \mathrm{p}=0.002$ & & & &
\end{tabular}

$\mathrm{X}^{2}(1)=10.077, \mathrm{p}=0.002$ 
Table 6: Materials used to wash hand by the respondents

\begin{tabular}{|c|c|c|c|}
\hline $\mathbf{S} / \mathbf{N}$ & Material & Number of Respondent & $\%$ \\
\hline 1. & Water only & 184 & 46.0 \\
\hline 2. & Water and soap & 196 & 49.0 \\
\hline 3. & Water and ash & 0 & 0 \\
\hline 4. & No response & 20 & 5.0 \\
\hline & Total & 400 & 100 \\
\hline
\end{tabular}

\section{DISCUSSION}

The study showed that majority of the respondents were between the ages of below 25 years, this is not surprising since this age group represents majorly the age range for students in tertiary institutions in Nigeria. On the accessibility of water for hand washing $51.0 \%$ of the respondents claimed that it is of great concern as majority do not have access to treated or public water, leading to employing of energy to fetch water from various distances for various usages and thus be miserly with the usage of water which is reflective in the respondents' attitude to use of non- running water $(67.0 \%)$ in the washing of hand, where confined water is repeatedly used, which further show the unhygienic habit and low knowledge of the respondents' habit of hand sanitization this may affect the period of hand wash, time of hand wash, and materials used for hand wash which are all pivotal to the amount of water used in hand washing. However, this is not exceptional as it is the problem of many developing countries lacking adequate water sources supporting Curtis et al., (2003). Meanwhile, the time of hand wash habit is critical to maintain hand hygiene, few respondents spent at least a minute, and this situation calls for more enlightenment on the methodology of hand wash.

The time of hand wash is crucial to maintain a disease free individual and a way of this is the prevention of faeco-oral transmission of diseases. However, only few respondents washed their hands after using toilets, a situation that can passively lead to transmission of cholera, diarrhea, amoebiasis and worm infestation. Hand wash with soaps according to World health Organization (2006) is the best practice to get rid of germs in the hands. The investigation shows that $49 \%$ used the combination of water and soap, while $46.0 \%$ used water only. This might be due to believe among the majority of the populace that soaps are only for bathing and laundry, rather than handwashing. This finding is in support of Songa (2015) who reported among hand washers was $12 \%$ compared to non-hand washers which was $88 \%$. This needs to be accepted with modicum of caution as some re-infection may not be symptomatic thus respondents might not take cognizance of the occurrence and their immunity level. And since faeco-oral transmission is an established route for self-infection, many of the respondents may not be aware of possibility of the re-infection since a few respondents $(24 \%)$ and $(31.0 \%)$ only washed hands after toileting and before meal. This is contrary to Songa (2015) who reported (58.9\%) and (58.3\%) respectively.

However, some reasons by the respondents on the correct disposition to hand wash hygiene included absent minded attitude, academic work stress, lack of knowledge of health implications and some level of water scarcity. The knowledge of hand hygiene amongst the respondents revealed that cholera $(32.0 \%)$ is the most recognized diseases known to be associated with contaminated hands followed by typhoid (16.0\%) and Ebola (10.0\%), this is contrary to Songa (2015), who reported diarrhea as the most known disease that is associated with poor hand hygiene. The 2014 outbreak of Ebola virus disease in Nigeria led to an increased awareness on the role of hand sanitizer in infection 
control (Nwabueze et al., 2016). While the use of Alcohol based hand sanitizer has been commonly recommended as means of hand hygiene at the outbreak of Ebola- Virus Disease (Wolfe et al.,2017). This is supportive of Mathur (2011) where the impact of hand hygiene in disease prevention has been well established and recently prescribed method of hygiene, possibly due to higher compliance rate associated with hand hygiene especially in areas lacking adequate water supply The usage of hand sanitizer though low in this investigation (17.8\%), has been described previously to reduce infection rate (Otokunefor and Princewill,2017 but may not ascertain total elimination of disease causing organisms such as Clostridium difficile spores whereas combination of soap and water do that effectively (Jabbar et al., 2010), as the findings is in support of Otokunefor and Princewill (2017) where a brand of hand sanitizer has not been effective in inhibiting two isolates of S.aureus and K. pneumonia and (Ochwoto et al., (2017 And where some hand sanitizer products were not against some isolates of microorganisms was attributed to composition of the sanitizer where alcohol based show higher efficacy than isopropyl based

\section{CONCLUSION}

Hand hygiene habit should be regarded as one of the ways of life to prevent diseases infliction in human irrespective of any impediments that could come up. Irregular washing of hands has been suspected to be the cause of diseases. It is important that individual is advised to improve on personal hygiene and hand sanitization by prescribed methods of hand washing by soaps and water or hand sanitizers after defecation and contacts of the hands with various body fluids that may habour any disease-causing organisms, which can cause self-infliction by oral and open body parts and infection transfer to another individual. The overall knowledge of hand sanitization amongst the undergraduate of Tai Solarin University was not poor, the practice should be encouraged. 


\section{REFERENCES}

Burton, M., Cribb, C., Donachie, P., Judah, G; Curtis, V., Schmidt, W.P. (2011). The effect of hand washing with water or soap on bacterial contamination of hands. International Journal of Environmental Research and Public Health 8(1) 97-104

Centres for Disease Control and Prevention (2013). Hand washing; clean hands save lives available at http://www.cdc.gov/handwashing/

Curtis, V and Cairncross,S (2003).Effect of washing hands with soaps on diarrhea risk in the community: a systematic review. Lancet Infectious Diseases3(5) 275-281

Curtis,V.C and Cairncross,S (2003). Water, sanitation and hygiene at Kyoto, British Medical Journal 327(7405): 34. doi: $10.1136 / \mathrm{bmj} .327 .7405 .3$

Didier, P., Benedectta, A and John, B (2009). The world health organization guidelines on hand hygiene in health care and their consensus recommendation. Infection Control and Hospital Epidemiology 30(7) 611-622. doi:10.1086/600379

Global Hand washing Partnership (2017). Planner's guide Global hand washing (6th ed., pp 1-81, FHI 360 partnership Washington, DC http: globalhandwashing.org-

Jabbar, U., Leischner, J., Kasper, D., Gerber, R., Sambol, S., Parada, J., Johnson, S and Gerdind, N (2010). Effectiveness of alcohol-based hand rubs for removal of Clostridium difficile spores from hands Infection Control and Hospital Epidemiology 31 (6) 565-570. doi:10.1086/652772

Mathur. P(2011)Hand hygiene: back to the basics of infection control. The Indian Journal of Medical Research 134(5) 611-620

Nair,S.S., Hanumantappa, R., Hiremath, S.G., Siraj, M.A and Raghunath, P (2014). Knowledge, attitude and practice of hand hygiene among medical and nursing students at a tertiary health care centre in Raichur, India. ISRN Preventive Medicine 6 608927.doi:10.1155/2014/608927

Nwabueze, S.A., Amah, C.C., Azuike, E.C., Anene, J.O., Kadiri-Eneh, N. P., Anameje, O.A and Akudu, A.C(2016).Ebola viral disease prevention: Perception of secondary school students in two districts in Anambra State, Nigeria. Issues in Scientific Research 1(1) 1-9

Ochwoto, M., Muit,, L., Talaam, K., Wanjala, C., Ogeto, F., Wachira, F., Osman, S., Kimotho, J and Ndegwa, L (2017). Anti-bacterial efficacy of alcohol hand rubs in the Kenyan market 2015. Antimicrobial Resistance and Infection Control 6(1) 17.https://doi.org/10.1186/s13756-017-0174-3

Oke, M. O.(2012) .Socio-environmental impact of higher institutions on host communities. Journal of Geography and Regional Planning. 5(50). 132-141.

Otokunefor, K; and Princewill, I (2017) Evaluation of antibacterial activity of hand sanitizer- an in vitro study, Journal of Applied Sciences and Environmental Management 21 (7) 1276-1280

Pires, D., Tartari, E., Bellissimo-Rodrigues, F and Pittest, D (2017). Why language matters: a tour through hand hygiene literature. Antimicrobial Resistance and Infection Control 665 https://doi.org/10.1186/s13756-0170218-8 
Reynolds, S.A., Levy, F and Walker, E.S (2006) Hand sanitizer alert, Emerging infectious diseases 12(3); 527-529

Songa J. (2015) Water, hygiene and Sanitation practices amongst medical students in Moi University, Eldoret, Kenya. International Journal of Biomedical Research 6 (10) 823-834. http:// doi.org/10.7439/ijbr V6i 10.2595

Songa, J., Van Roekel, K., Mwangi, J and Noel, L (2015). A Study on hand washing practices among health care workers in Embu referral hospital Embu County. Pinnacle Medicine and Medical Sciences ISSN 2360-9516, 2 (6) Article ID pmms _206,780-784

Wolfe, M.K., Gallandat, K., Daniels, K., Desmarais,A.M.,Scheinman, P and Lantagne, D. (2017) Handwashing and ebola virus disease outbreaks. A randomized comparison of soap, hand sanitizer and $0.05 \%$ Chlorine solution on the inactivation and removal of model organism Phi 6 and E. coli from hands and persistence in rinse water PLOS ONE 12(2) e0172734 .doi; 10.1371/journal.pone0172734

World Health Organization (2009).W.H. O guidelines on hand hygiene in health care, First Global Patient Safety Challenge. Clean Care is safer care. Geneva, Switzerland 64pp

Zapka, C., Leff, J.,Henley, J., Tittl, J., De Nardo, E., Butler, M., Griggs, R., Fierer, N and Edmonds-Wilson, S (2017). Comparison of Standard culture- based method to culture-independent method for evaluation of hygiene effects on the hand microbiome. mBio.8(2): e00093-17 